\title{
Memory Effect of Aquatic Biofilms in the Partitioning of Polycyclic Aromatic Hydrocarbons (PAHs) and Polychlorinated Biphenyls (PCBs) in Water Streams
}

\author{
Giacomo Bertini
}

\begin{abstract}
Polycyclic aromatic hydrocarbons (PAHs) and polychlorinated biphenyls (PCBs) are ubiquitous pollutants in the environment. Due to their physical-chemical properties, PAHs and PCBs can be accumulated in organic matrices such as living organisms, soil and sludge. Their toxicity and mutagenicity is a serious concern. In many cases an effective strategy to assess the pollution of water streams is to detect these compounds using biofilms, sediment and sludge as passive samplers.

However, the absorption of hydrophobic compounds in biofilms is a reversible mechanism. The molecules of a specific pollutant can be desorbed back into the water column when specific conditions have changed. Furthermore, those molecules could be biodegraded by the microorganisms living inside that biofilm.

Thus, the pollutant is not going to remain detectable inside that biofilm sample permanently, but only for a limited time. This is due to the memory effect.

The aim of this work is to retrieve the most relevant data on this subject and build from scratch a simplified model. This will help to understand how microbial biofilms can influence the distribution of PAHs and PCBs in water streams.

Absorption, desorption and biodegradation are the three main mechanisms considered for the calculations.

This information will surely stimulate further research on this topic. Phenanthrene and pyrene were chosen as reference compounds for PAHs and Kaneclor 300, Aroclor 1260 and other tri- and tetra- chlorinated byphenils were chosen as reference for PCBs.
\end{abstract}

Index Terms-Sorption, memory, biofilms, polycyclic aromatic hydrocarbons.

\section{INTRODUCTION}

Since the 80 s an increasing environmental awareness at an international level led to the adoption of new specific legislations for monitoring persistent organic pollutants (POP) in air, soil and water [1]-[3]. Several classes of organic compounds have been listed as priority pollutants and related environmental monitoring procedures acquired great relevance.

Polycyclic aromatic hydrocarbons (PAH) are a major concern of pollution due to their toxicity and their ubiquitous occurrence in air, soil, surface water, waste water and sewage

Manuscript received February 18, 2016; revised April 21, 2016. This work was supported by the FP7 funding program of the European Communityas a part of the Marie Curie Early Stage Research training ATWARM (Advanced Technologies for Water Resource Management) and was prepared as part of a $\mathrm{PhD}$ research at the Biofilm Centre, University of Duisburg-Essen, Germany.

Giacomo Bertini is with the Prozess Analysen Instrumente GmbH, Hipstedt, Germany (e-mail: gcmbertni@gmail.com). sludge [4], [5]. On a global scale around $85 \%$ of the emitted PAHs are represented by low molecular weight PAHs, such as naphtalene, phenanthrene, acenaphtilene, acenaphthene, fluorine, fluoranthene, pyrene, anthracene, whereas the high molecular weight PAHs cover only the least of the overall emission [6]. Within this investigation, phenanthrene and pyrene are the reference PAH compounds due to their high environmental occurrence. The main properties of PAHs are low solubility, high vapor pressure, high octanol-water and octanol-air partitioning coefficient [7], [8]. Polychlorinated biphenyls (PCBs) are a class of POP, in which two or more chlorine atoms are attached to a molecule of biphenyl [9]. Although their industrial production and their use in open systems has been prohibited since late 70s in most countries, PCBs are still among the most common POP found in the environment. These compounds were used extensively within several industrial processes [10]. The fall out of PCBs in the environment is in part the result of their accumulation in soil, sediments and living organisms, which took place in those years. PCBs can be released also by combustion of coal in power stations, burning of coal and wood for domestic and municipal heating, incineration of waste and fortuitous events like fires [10]: PCBs display low water solubility, high thermal and chemical stability and high dielectric constant.

In aquatic environments, biofilms colonize most of the solid-liquid interfaces and can absorb and accumulate dissolved organic pollutants. Biofilms are microbial aggregates, in which bacterial cells are enveloped by a matrix of self-produced extracellular polymeric substances (EPS) such as polysaccharides, proteins, lipids, humic acids and DNA [11]. In rivers and water streams, microbial biofilms can absorb, accumulate and biodegrade organic pollutants [12]-[15]. Polar hydrophilic pollutants are accumulated in biofilms due to strong electric interactions, whereas the sorption of hydrophobic organic pollutants in the EPS matrix of biofilms is mostly diffusive [16] and driven by the establishments of weak interactions between the functional groups of the EPS polymers and the sorbed molecules. Also the secondary structure of the EPS matrix affects the diffusivity of the absorbed molecules by obstruction [17]-[20]. It is known that biofilms can be both sinks and sources of hydrophobic pollutants in aquatic systems. Under specific conditions (e.g. change in ionic strength and $\mathrm{pH}$ of the water phase), desorption of the absorbed molecules can occur [21], [22]. The sorption mechanism is indeed a reversible phenomenon.

Desorption is not the only mechanism, which influences the fate of hydrophobic compounds (HOC) in biofilms. Once absorbed, the molecules of PAHs can undergo aerobic and anaerobic biodegradation [23], whereas PCBs such as di-, 
tri-chlorinated biphenyls are biodegraded prevalently aerobically [24]. Highly chlorinated PCBs, with more than four chlorine atoms seem biorefractory to aerobic bacteria. Assuming thata time-limited event of pollution within a water stream takes place, it is possible to delineate a simplified scenario (Fig. 1).

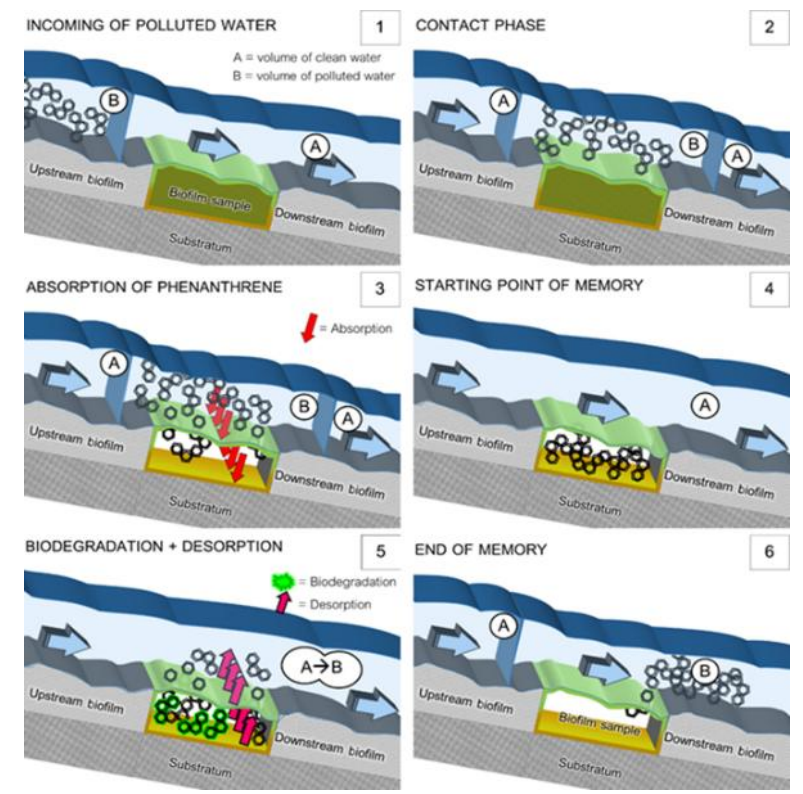

Fig. 1. Sketch of the absorption, desorption and biodegradation of phenanthrene in a sample of aquatic biofilm under dominant flowing conditions.

When a volume of contaminated water" $\mathrm{B}$ " gets in contact with a certain surface of a biofilm (Fig. 1.1 and 1.2), absorption of the dissolved pollutant into the biofilm begins (Fig. 1.3). The absorption is driven by the gradient of concentration between the inner biofilm and the water phase and it goes on untillthe equilibrium is reached.After some time, the pollution event ends and the volume of polluted water flows over the biofilm, proceeding its course downstream. The following clean water phase "A", which gets in contact with the biofilm immediately after,does not contain the pollutant (Fig. 1.4). At this point, an opposite gradient of concentration between the inner biofilm and the water phase is established and it promotes the diffusion of the molecules outside from the biofilm [25]. Now the volume of water "A"contains the pollutant and becomes "B" (Fig. 1.5). This water volume " $\mathrm{B}$ " transports the pollutant further along the water stream (Fig. 1.6). This desorption mechanism occurs while the microbial communities in the biofilm degrade part of the pollutantmolecules (Fig. 1.5). Thus, desorption and biodegradation cause the depletion of the pollutant inside the biofilm matrix. This generatesa memory effect. The amount of pollutant in the biofilm will not remain detectable inside the biofilm indefinitely. When biofilms, sludge and sediments are analyzed in order to trace pollutants in water systems, the memory effect becomes one of the main parameters, which need to be investigated. It tells us how long the pollutant will be detectable inside the biofilm after a specific pollution event has occurred.

Although biofilms have been already exploited for monitoring PAHs, PCBs and other hydrophobic pollutants in contaminated water streams [26]-[29], this critical aspect has never been considered. What is the extent of the memory effect? If the pollutant is not detected inside a biofilm sample, how can one know if the pollutant has ever been travelling that water stream in thefirst place? Can one monitor pollutants in water bodies using microbial biofilms without this information?

The aim of this manuscript is to provide the reader with answers to these questions using previously published data. Kinetic models for the sorption of PAHs, PCBs and other pollutants have been published and biofilm properties are well known.

In the next chapters three simplified models will be described. The memory effect will be calculated in three different ways. At first it will be described considering biodegradation and desorption separately. At the end, the simultaneous influence of both biodegradation and desorption will be used to calculate the final extent of the memory effect. This will facilitate the review of all data.

\section{Calculations}

In this chapter it is explained how the extent of the memory effect has been calculated. The math required is very simple. Raw published values have been collected from the literature and used to implement a well-known kinetic model.

However, few considerations are necessary.

As previously explained, the main mechanisms which influence the residence time of an absorbed molecule inside the biofilm matrix after absorption equilibrium has been reached are biodegradation and desorption. These two mechanisms occur simultaneously, and therefore depending on their kinetics, they might influence each other. This will be considered and described later.

Biodegradation rates for both PAHs and PCBs in biofilms and surrogate matrices have abundantly published. They can be exploited easily. On the contrary desorption rates for these pollutants have not been reported yet and therefore it is necessary to choose a mathematical function, which can describe the kinetic of this mechanism. According to the available data, a first order kinetic function seems to be the most used tool for studying the sorption of organic compounds inside gel-like matrices, biofilms and surface sediments [29]-[37].

This function is outlined in Equation (1):

$$
\frac{d C}{d t}=k C_{n}
$$

where $n$ is the order of the kinetic, $\mathrm{k}$ is the rate constant $\left(\mathrm{t}^{-1}\right)$, $C$ is the concentration of pollutant in the biofilm $(\mathrm{mg} / \mathrm{L})$ and $\mathrm{t}$ is the time.

However, the kinetic function alone does not quite suffice. It is still necessary to calculate the concentration of the pollutant inside the biofilm at the beginning of the desorption process. This concentration is primarily the absorption equilibrium concentration of the pollutant in the biofilm matrix. This value will be the concentration from which the desorption and the biodegradation together will start to affect the extent of the memory effect. This would happen after the concentration of the pollutant in the outer water phase has dropped down to zero.

This is how the concentration of the pollutant is calculated:

$$
S_{w} K_{d}=C
$$


$S_{w}$ stands for the solubility $(\mathrm{mg} / \mathrm{L})$ of the pollutant in water and $K_{d}$ is the equilibrium partition coefficient of the pollutant between the water phase and the inner biofilm's matrix.

In order to calculate this concentration $C$, reference values of distribution coefficients $\left(K_{d}\right)$ and water solubility of each class of compounds were collected from other studies. The solubility of pyrene and phenanthrene in water is $0.18 \mathrm{mg} / \mathrm{L}$ and $1.5 \mathrm{mg} / \mathrm{L}$ respectively [38], [8]. The reference PCBs display a water solubility of $0.2-0.9 \mathrm{mg} / \mathrm{L} \mathrm{[39].The} \mathrm{modeling}$ refers to the molecules of the pollutant which are dissolved into the water phase, since these are the molecules involved in the partitioning process. The choice of a suitable partition coefficient will be presented in the next section.

At last, one further consideration. The desorption of PAHs and PCBs from surface sediments and similar organic matrices is often modeled as a monophasic or a biphasic mechanism. The biphasic model involves the use of two different values of rate constants: fast rate constant and slow rate constant. These values can vary from each other for three or four orders of magnitude [40]-[42]. These two different values will be also considered for the calculation of the desorption rates.

\section{A. Partition Coefficients}

In order to solve the equation 1 , it is necessary to find a suitable partition coefficient. Knowing the solubility of a reference pollutant in water, the partition coefficient gives information on its concentrations in the biofilm at the equilibrium of the absorption mechanism. The octanol-water partition coefficient $\left(K_{o w}\right)$ and the organic carbon partition coefficient $\left(K_{o c}\right)$ are the most common parameters used to study the sorption properties of biofilms. The $K_{o c}$ is calculated by the ratio between the distribution coefficient biofilm-water $\left(K_{d}\right)$, which is normalized to the dry weight, and the organic carbon fraction $\left(f_{o c}\right)$ of the biofilm [30]. The $K_{o c}$ of phenanthrene and pyrene for microbial biofilms has been reported as equal to $12.400(\mathrm{~L} / \mathrm{Kg})$ and $38.000(\mathrm{~L} / \mathrm{Kg})$ respectively [30]. The octanol-water partition coefficient $K_{o w}$ is the value obtained by the ratio of the molar concentrations of a compound taken at the equilibrium of the partitioning between water and n-octanol. The $K_{o w}$ of phenanthrene and pyrene have been previously measured and reported as equal to $28.000(\mathrm{~L} / \mathrm{Kg})$ and $75.000(\mathrm{~L} / \mathrm{Kg})$ respectively [43], [44]. The $K_{o c}$ of 2-CBs, 3-CBs and 4-CBs has been reported as equal to $104-106(\mathrm{~L} / \mathrm{Kg})$ and the $K_{o w}$ as equal to $104-108$ $(\mathrm{L} / \mathrm{Kg})$ [45], [46]. These values indicate that at the equilibrium of the partitioning process, the concentration of the pollutants inside the organic fraction of the biofilm would be several times higher than their water solubility. Although widely used, these parameters will not be considered in this work. They display some limitations, which are extensively described elsewhere [47], [48].

Instead, another parameter will be of more help: the distribution coefficient $K_{d}$. This coefficient is the result of the ratio between the volume concentrations of a compound in two immiscible phases at the equilibrium of the partitioning. Due to a lack of published $K_{d}$ values for biofilms, other reference matrices must be considered. For instance, polysaccharide gels and low organic carbon aquifer sediments. Polysaccharide gels have been previously used as suitable models for studying the sorption of organic compounds in biofilms [49], [50]. Gellan gels for instance may be a suitable surrogate for biofilms [51]. Some authors tested the partitioning of phenanthrene between gellan gels and water. They reported an equilibrium distribution coefficient of 1.5 [52], [53]. Useful data was published also by other authors, who studied the sorption of pyrene and phenanthrene onto low organic carbon aquifer sediments and alginate beads [54]- [56]. According to all these studies, the $K_{d}$ of pyrene is equal to $5-8$ and the $K_{d}$ of phenanthrene ranges between 1.0 and 2.7. The $K_{d}$ values of PCBs, which were reported for model matrices such as alginate beads, surface sediments and sludge, are equal to 10-75 [37], [57][59].

Once all variables have been collected, the value of the desorption rate for PAHs and PCBs in biofilms has been obtained inserting the raw numbers in the kinetic function previously described (Equation (1) and (2)).

Using the $K_{d}$ values of phenanthrene and pyrene and of the reference PCBs presented before, according to the Equation (2) it was possible to estimate the initial concentration of pollutant within the biofilm (C). The values of C are $2.4 \mathrm{mg} / \mathrm{L}$ and $1.4 \mathrm{mg} / \mathrm{l}$ for phenanthrene and pyrene respectively and between $2 \mathrm{mg} / \mathrm{L}$ and $15 \mathrm{mg} / \mathrm{L}$ for the PCBs.

\section{BIODEGRADATION MODEL}

In this first model the desorption mechanism is not considered. The values presented here will be exploitedin the last chapter, in order to have a better overview of the involved mechanisms. In Table I the degradation rates of reference compounds in biofilms and river sediments are listed. These values are reported from previous studies.

The result is a "biodegradation-based" memory effect of 1.2 - 10 days for phenanthrene and of $1.8-7.2$ days for pyrene.

PCBs display much faster biodegradation rates within biofilms. In this case, the memory effect of a biofilm sample would last between 5 hours and 1.75 days (Table I).

Only one previous study has presented unequivocal results on the biodegradation kinetics of phenanthrene and pyrene inside a microbial biofilm. Zhang and colleagues observed that within the biofilm phenanthrene and pyrene had been almost completely biodegraded after 3-5 days [60]. This is in agreement with the model presented here.

TABLE I: BIODEGRADATION RATES OF PCBS AND PAHS IN BIOFILMS AND REFERENCE MATRICES

\begin{tabular}{|c|c|l|}
\hline Compound & $\begin{array}{c}\text { Biodegr.rate } \\
\left(\mathrm{mg} / \mathrm{L} \text { day }^{-1}\right)\end{array}$ & \multicolumn{1}{c|}{ Sorbent system } \\
\hline phenanthrene & 0.3 & phenanthrene crystals[61] \\
\hline & $0.2-0.3$ & Hydrophobic membrane[62] \\
\hline & $0.1-0.4$ & marine sediments[63] \\
\hline & 2 & packed bed column reactor[64] \\
\hline & $0.9-1$ & mulch biofilm barrier[65] \\
\hline pyrene & 0.6 & on phenanthrene crystals[63] \\
\hline & 0.2 & packed bed column reactor[62] \\
\hline Declor 103 & 0.8 & mulch biofilm barrier[65] \\
\hline 4-CB cogeners & 5.6 & Immobilized bacteria in alginate[66] \\
\hline Kaneclor 300 & 10 & Biofilm on glass beads[67] \\
\hline Aroclor 1260 & $1.8-10$ & Biofilm in fluidized bed reactor[69] \\
\hline
\end{tabular}




\section{DESORPTION MODEL}

The remobilization of pollutants from biofilms can occur via detachment of the biofilm matrix from the substratum or via diffusional desorption of the pollutant molecules into the water column. Both mechanisms can influence the release of PAHs and PCBs in the water. However, the detachment of physical portions of the biofilm can be due to several factors, some of which involve also unpredictable events such as predator grazing or temporary increase of shear forces [70]. These mechanisms will not be considered here, since they are the result of not reproducible events. Desorption instead is regulated by physical-chemical properties of biofilms, which have been modeled and investigated before.

Whenever unequivocal data for biofilms was missing, reported results on reference matrices have been exploited. These surrogates would be biofilm-like sorbents such as sludge, sediments and immobilized cells in hydrogels. High percentage of reversibility was observed for the absorption of HOC in all these surrogates.

Under batch shacking conditions, for all the studies, 70-90\% of the absorbed molecules were desorbed back into the water phase [27], [29], [71]- [75]. It is necessary to point out that most of that reference research has been focused on bio-removal purposes and all desorption tests were planned as "regeneration procedures" in batch shacking systems. This aspect must be taken under consideration. In fact, the desorption of hydrophobic organic compounds (HOC) from these matrices, is significantly affected by a lack of flow conditions and by the effect of the gradient of concentration on the partitioning of the pollutants between the sorbent phase and the solvent phase (Fig. 1). It is fair to say that the flow of the water over the biofilm surface could increase this percentage and therefore the kinetics of desorption are expected to be significantly faster. The laminar flow rate increases the mass transfer between solid-liquid systems [76]. One more reason to assume that the absorption of those pollutants on river biofilms under dynamic conditions is a reversible process.

Reversibility and fast kinetics have been observed indeed for the desorption of phenanthrene and pyrene in sediments with low organic carbon content, soil-slurry systems and sludge (Table II) [55], [63], [77], [78].

The rate constant values reported from previous studies, have been exploited in order to calculate the desorption rate based on the Equation 1. Following this model, the memory effect on pyrene and phenanthrenehas been calculated as equal to 0.4-20 hours and 0.5-2.5 hours respectively. At leas for phenanthrene, this result seems to confirm another recently published value of 2.5 hours, which was observed for the desorption of phenanthrene from a polysaccharide gel slab, used as model of aquatic biofilms [53]. For pyrene no published data were found, which could confirm these numbers. According to this monophasic desorption model, the biodegradation rate does not influence significantly the memory effect of a biofilm onphenanthrene and pyrene, because its values range from 1 days to 10 days. The desorption mechanism causes a faster depletion of the pollutant than the biodegradation. For PAHs, the biodegradation is very slow and has no significant influence.

On the contrary, the desorption rates for the PCBs presented in Table II are much lower than for PAHs. The memory effect on the reference PCBs listed in Table IIis equal to 27-55 hours. In this case the desorption has not a significant influence and the memory effectis defined by the biodegradation rates only. (Table I and II).

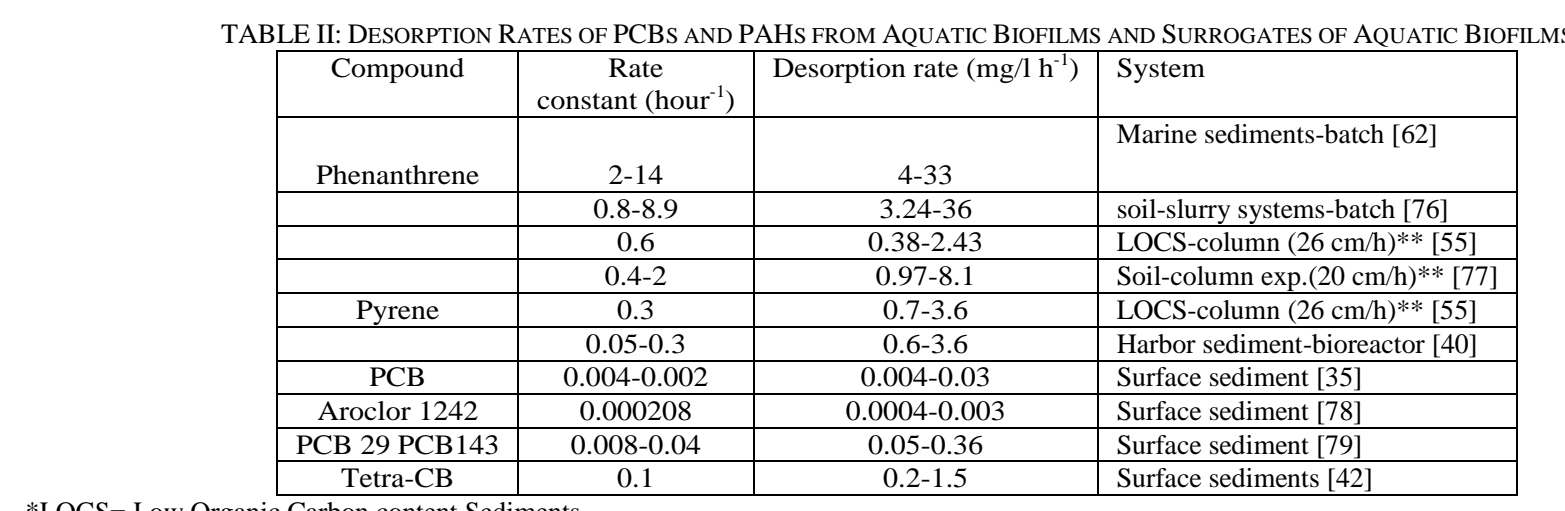

*LOCS $=$ Low Organic Carbon content Sediments.

$* *$ The flow velocity of the water phase during the experiment have been mentioned only in some of the reference studies.

\section{BIPHASIC MODEL}

The desorption of PAHs and PCBs from aquatic sediments and aquatic materials has been modeled as a two steps mechanism: a first fast desorption, followed by a slow desorption. The slow rate constants are equal to $0.3-1.8 * 10^{-3}$ $\mathrm{h}^{-1}$ for PAHs and $1-8 * 10^{-4} \mathrm{~h}^{-1}$ per PCBs. These values are three or four orders of magnitude smaller than the values reported in Table II [40]-[42], [81]- [83]. According to this model, $70 \%-90 \%$ of the PAH molecules and $60 \%-80 \%$ of the PCB molecules are desorbed following initial fast desorption kinetics, while the remaining portion, $10 \%-30 \%$ for PAHs and $20 \% .40 \%$ for PCBs, is desorbed with slow rate constants. The second desorption phase involves the molecules strongly associated with the matrix. If the biodegradation is not acknowledged, the memory of a biofilm sample for PAHs and PCBs would last about 70 days and 90 days respectively.

But the biodegradation of PAHs would play a crucial role during the second phase of slow desorption. The diffusional desorption rates of phenanthrene and pyrene in the second phase $\left(0.7 \times 10^{-3} \mathrm{mg} / \mathrm{Lh}^{-1}\right.$ and $\left.0.4 \times 10^{-3} \mathrm{mg} / \mathrm{Lh}^{-1}\right)$ are significantly smaller than the biodegradation rates $(0.2-2$ $\mathrm{mg} / \mathrm{Ld}^{-1}$ and $0.2-0.8 \mathrm{mg} / \mathrm{L} \mathrm{d}^{-1}$ ). In this phase the biodegradation is the main process and the desorption is irrelevant. During this stage the extent of the memory effect onphenanthreneis 0.4-3.6 days and on pyrene is 0.5-2.15 days. The memory effect onphenanthrene and on pyrene during the 
first desorption phase is 3.4 hours and 3.3 hours respectively. The overall memory effect is obtained adding the value from the first phase to the value of the second phase. Its extent on phenanthrene ranges between 13 hours and 91 hours, while on pyrene it is around 15.3-54.9 hours.

On the contrary, the biodegradation of PCBs in biofilms seems to influence both first and second phase of desorption significantly. In fact, the biodegradation of PCBs in biofilm is the main depletion mechanism during both phases. The biodegradation rate of $\mathrm{PCB}$ is $0.4 \mathrm{mg} / \mathrm{L} \mathrm{h}^{-1}$. This value is comparable to the desorption rate of the first phase $(0.35$ $\left.\mathrm{mg} / \mathrm{L} \mathrm{h}^{-1}\right)$ and significantly higher than the desorption rate of the second phase $\left(1-8^{*} 10^{-4} \mathrm{~h}^{-1}\right)$. According to the biphasic model, the overall memory of a biofilm sample for PCBs would be equal to 2-30 hours depending on the chlorination of the molecules.

\section{CONCLUSION}

A review of previously published desorption and biodegradation rates of reference $\mathrm{PAHs}$ and $\mathrm{PCB}$ s from river sediments, sludge and hydrogel matrices was carried out in order to measure the memory effect of aquatic biofilms on the partitioning of these pollutants. In particular, the memory effect under dominant flowing conditions was described. Both monophasic and biphasic models were outlined. According to empiric studies, the biphasic model seems to be a more correct model than the monophasic model, for describing desorption kinetics of HOC in water from model organic matrices. For them, the desorption hysteresis was reported by various authors [40], [80]-[85].

Some published investigations are also focused on the effect of surfactants on desorption and biodegradation of the compounds in aquatic biofilms [86], [87]. This aspect was not debated here, but the presence of surfactants in the water phase during desorption, it is expected to decrease the value of the memory effect.

From the results of this investigation, the retention and availability of PAHs and PCBs in aquatic biofilm samples lasts 1-3 days. Sampling procedures, which are carried out by longer sampling intervals, are not reliable for assessing pollution along a water stream using aquatic biofilms as passive samplers. Contrary to what is assumed in many cases, the memory effect on PAHs and PCBs seems to last only shortly. Empirical studies, which report the accumulation of these pollutants in epilithic biofilms within intervals of months, are likely to be the result of shorter and subsequent absorption-desorption cycles and simultaneous biodegradation. These cycles might have been disregarded during those investigations [27], [88]. In other cases, as previously explained, the use of not suitable partition coefficients $\left(K_{o c}\right.$ and $K_{o w}$ ) could cause the overestimation of the retention times of HOC in aquatic biofilms [19], [30]. The main results produced by this work fully matches what has been observed by previous field and laboratory studies [29], [53], [89]. This new information is crucial to avoid false results for monitoring $\mathrm{PAHs}$ and $\mathrm{PCBs}$ in rivers and water streams.

All raw data contained in this manuscript have been already published elsewhere, but no one before has ever used them in order to model the partitioning of PAHs and PCBs between biofilms and water under dynamic conditions.

Surrogate matrices have been extensively used as reference to support this interpretation. Microbial biofilms are highly heterogeneous systems in the environment and their sorption properties are not fully understood. Actual values of distribution coefficients and desorption rates for PAHs in biofilms are missing and only few values were published for PCBs. The knowledge we have about biofilms only wouldn't have been enough to complete this study. This is why other matrices with similar properties have been included as surrogates of biofilms.

An important aim of this work is to stimulate new research, so that the memory effect of aquatic biofilms on hydrophobic organic compounds in water streams can be studied more systematically for monitoring purposes.

\section{APPENDIX}

Appendixes, if needed, appear before the acknowledgment.

\section{ACKNOWLEDGMENT}

This study was carried out from December 2010 to November 2014 as part of the early stage Ph.D. project 2.5 (ESR 2.5) funded by the Marie Curie FP7 initiative A.T.W.A.R.M (Advanced Technologies for Water Resource Management). The hosting institution was the Biofilm Centre of the University of Duisburg-Essen.

\section{REFERENCES}

[1] N. Estoppey et al., "Low density polyethylene (LDPE) passive samplers for the investigation of polychlorinated biphenyl (PCB) point sources in rivers," Chemo-Sphere, vol. 118, pp. 268-276, 2015.

[2] A. Carpi and A. J. Schweighardt, "Forensic environmental chemistry," Forensic Chemistry Handbook, pp. 1-22, 2012.

[3] M. A. Drumbl, "Actors and law making in international en-vironmental law," Research Handbook on International Environmental Law, Edward Elgar Publishing Inc, Cheltenham, pp. 3-25, 2010.

[4] K. Srogi, "Monitoring of environmental exposure to poly-cyclic aromatic hydrocarbons: A review," Environmental Chemistry Letters, vol. 5, no. 4, pp. 169-195, 2007.

[5] S. O. Baek et al., "A review of atmospheric polycyclic aro-matic hydrocarbons: sources, fate and behavior," Water, Air, and Soil Pollution, vol. 60, no. 3-4, pp. 279-300, 1991.

[6] C. T. Chiou et al., "Water solubility enhancement of some organic pollutants and pesticides by dissolved humic and fulvic acids," Environmental Science \& Technology, vol. 20, no. 5, pp. 502-508, 1986.

[7] Y. Zhang and S. Tao, "Global atmospheric emission inventory of polycyclic aromatic hydrocarbons (PAHs) for 2004," Atmospheric Environment, vol. 43, no. 4, pp. 812-819, 2009.

[8] L. E. Sverdrup, T. Nielsen, and P. H. Krogh, "Soil ecotoxicity of polycyclic aromatic hydrocarbons in relation to soil sorption, lipophilicity, and water solubility," Environmental Science \& Technology, vol. 36, no. 11, pp. 2429-2435, 2002.

[9] L. W. Robertson and L. G. Hansen, PCBs: Recent Advances in Environmental Toxicology and Health Effects, University Press of Kentucky, 2015.

[10] L. Wolska et al., "Polychlorinated biphenyls (PCBs) in bottom sediments: Identification of sources," Chemosphere, vol. 111, pp. 151-156, 2014.

[11] H. C. Flemming and J. Wingender, "The biofilm matrix," Nature Reviews Microbiology, vol. 8, no. 9, pp. 623-633, 2010.

[12] L. M. Abriola, "Modeling multiphase migration of organic chemicals in groundwater systems-a review and assessment," Environmental Health Perspectives, vol. 83, p. 117, 1989.

[13] T. Zhang et al., "Stimulating the anaerobic degradation of aromatic hydrocarbons in contaminated sediments by providing an electrode as the electron acceptor," Environmental Microbiology, vol. 12, no. 4, pp. 1011-1020, 2010. 
[14] L. J. Liermann et al., "Microenvironments of $\mathrm{pH}$ in biofilms grown on dissolving silicate surfaces," Chemical Geology, vol. 171, no. 1, pp. 1-16, 2000.

[15] Q. Duan et al., "Flagella and bacterial pathogenicity," Journal of Basic Microbiology, vol. 53, no. 1, pp. 1-8, 2013.

[16] P. S. Stewart, "Mini-review: Convection around biofilms," Biofouling, vol. 28, no. 2, pp. 187-198, 2012.

[17] M. Vogt, H. C. Flemming, and W. S. Veeman, "Diffusion in Pseudomonas aeruginosa biofilms: A pulsed field gradient NMR study," Journal of Biotechnology, vol. 77, no. 1, pp. 137-146, 2000.

[18] E. E. Beuling et al., "Characterization of the diffusive properties of biofilms using pulsed field gradient-nuclear magnetic resonance," Biotechnology and Bioengineering, vol. 60, no. 3, pp. 283-291, 1998.

[19] D. Wicke, U. Böckelmann, and T. Reemtsma, "Environmental influences on the partitioning and diffusion of hydro-phobic organic contaminants in microbial biofilms," Environmental Science \& Technology, vol. 42, no. 6, pp. 1990-1996, 2008.

[20] D. B. Wunder, V. A. Bosscher, R. C. Cok, and R. M. Hozalski, "Sorption of antibiotics to biofilm," Water Research, vol. 45, no. 6, pp. 2270-2280, 2011

[21] G. M. Wolfaardt et al., "Bioaccumulation of the herbicide diclofop in extracel-lular polymers and its utilization by a biofilm community during starvation," Applied and Environmental Microbiology, vol. 61 , no. 1, pp. 152-158, 1995 .

[22] P. Y. Ancion et al., "Metal concentrations in stream biofilm and sediments and their potential to explain biofilm microbial community structure," Environmental Pollution, vol. 173, pp. 117-124, 2013.

[23] A. K. Haritash and C. P. Kaushik, "Biodegradation aspects of polycyclic aromatic hydrocarbons (PAHs): A review," Journal of Hazardous Materials, vol. 169, no. 1, pp. 1-15, 2009.

[24] V. P. Singh and R. D. Stapleton Jr, "Microbial degradation of polychlorinated biphenyls (PCBs) in the environment," Biotransformations: Bioremediation Technology for Health and Environmental Protection, vol. 36, no. 29, 2002.

[25] T. Romeo, Bacterial Biofilms, Hidelberg: Springer, p. 295, 2008.

[26] E. Antusch et al., "Organische Schadstoffe in der Sielhaut: Sorptionsverhalten, Einflussgrössen und Entwicklungeinerpraktikablen Anaylsemethode: Sielhaut-kataster der Stadt Zürich," GWA, vol. 75, no. 11, pp. 1010-1016, 1995.

[27] M. Schorer and M. Eisele, "Accumulation of inorganic and organic pollutants by biofilms in the aquatic environment," Water, Air, and Soil Pollution, vol. 99, no. 1-4, pp. 651-659, 1997.

[28] H. P. Kaballo and P. A. Wilderer, "Das sequencing batch biofilm reactor (SBBR-) verfahrenzur reinigung von chloror-ganischbelasteten AbwässernimLeistungsvergleichmiteinembaugleichenkontinuierliche n Biofilmverfahren," 1998.

[29] J. V. Headley et al., "Rates of sorption and partitioning of contaminants in river biofilm," Environmental Science \& Technology, vol. 32, no. 24 pp. 3968-3973, 1998.

[30] D. Wicke, U. Böckelmann, and T. Reemtsma, "Experimental and modeling approach to study sorption of dissolved hydrophobic organic contaminants to microbial biofilms," Water Research, vol. 41, no. 10 pp. 2202-2210, 2007

[31] O. S. Amodu, S. K. O. Ntwampe, and T. V. Ojumu, "Bio availability of high molecular weight polycyclic aromatic hydro-carbons using renewable resources," INTECH Open Access Publisher, 2013.

[32] L. Yang, M. Jin, C. Tong, and S. Xie, "Study of dynamic sorption and desorption of polycyclic aromatic hydrocarbons in siltyclay soil," Journal of Hazardous Materials, vol. 244, pp. 77-85, 2013.

[33] R. M. Allen-King, P. Grathwohl, and W. P. Ball, "New modeling paradigms for the sorption of hydrophobic organic chemicals to heterogeneous carbonaceous matter in soils, sed-iments, and rocks," Advances in Water Resources, vol. 25, no. 8, pp. 985-1016, 2002.

[34] J. A. Field and R. Sierra-Alvarez, "Microbial transformation and degradation of polychlorinated biphenyls," Environmental Pollution, vol. 155, no. 1, pp. 1-12, 2008.

[35] J. T. Coates and A. W. Elzerman, "Desorption kinetics for selected PCB congeners from river sediments," Journal of Contaminant Hydrology, vol. 1, no. 1, pp. 191-210, 1986.

[36] H. Wang et al., "The response of a laboratory stream system to PCB exposure: study of periphytic and sediment accumulation patterns," Water Research, vol. 33, no. 18, pp. 3749-3761, 1999.

[37] S. Barreca, S. Orecchio, and A. Pace, "The effect of montmorillonite clay in alginate gel beads for polychlorinated biphenyl adsorption: Isothermal and kinetic studies," Applied Clay Science, vol. 99, pp. 220-228, 2014

[38] L. Eastcott, W. Y. Shiu, and D. Mackay, "Environmentally relevant physical-chemical properties of hydrocarbons: a review of data and development of simple correlations," Oil and Chemical Pollution, vol. 4, no. 3, pp. 191-216, 1988.
[39] R. Tehrani and B. Aken, "Hydroxylated polychlorinated biphenyls in the environment: Sources, fate, and toxicities," Environmental Science and Pollution Research, vol. 21, no. 10, pp. 6334-6345, 2014.

[40] G. Cornelissen, H. Rigterink, M. M. Ferdinandy, and P. C. Noort, "Rapidly desorbing fractions of PAHs in contaminated sediments as a predictor of the extent of bioremediation," Environmental Science \& Technology, vol. 32, no. 7, pp. 966-970, 1998.

[41] U. Ghosh, J. W. Talley, and R. G. Luthy, "Particle-scale investigation of PAH desorption kinetics and thermodynamics from sediment," Environmental Science \& Technology, vol. 35, no. 17, pp. 3468-3475, 2001.

[42] G. Cornelissen K. A. Hassell et al., "Slow desorption of PCBs and chlorobenzenes from soils and sedi-ments: relations with sorbent and sorbate characteristics," Environmental Pollution, vol. 108, no. 1, pp. 69-80, 2000

[43] Y. Gao and W. Ling, "Comparison for plant uptake of phe-nanthrene and pyrene from soil and water," Biology and Fertility of Soils, vol. 42, no. 5, pp. 387-394, 2006

[44] J. N. Huckins et al., "Development of the permeability/performance reference compound approach for in situ calibration of semipermeable membrane devices," Environmental Science \& Technology, vol. 36, no. 1, pp. 85-91, 2002

[45] L. Jiao, "QSPR study on the soil-water partition coefficient of polychlorinated biphenyls by using artificial neural network," Advanced Materials Research, vol. 455, pp. 930-934, 2012.

[46] F. L. Zhang et al., "Estimation of noctanol/water partition coefficients ( $\log$ ) of polychlorinated biphenyls by using quantum chemical descriptors and partial least squares," Journal of Chemistry, 2013.

[47] A. G. Ahangar, "Potential causes of organic carbon nor-malized partition coefficient (KOC) variability for organic com-pounds," A Scientific Research and Essays, vol. 6, no. 11, pp. 2228-2233, 2011.

[48] J. L. Hermens et al., "The octanol-water partition coefficient: Strengths and limitations," Environmental Toxicology and Chemistry, vol. 32, no. 4, pp. 732-733, 2013.

[49] E. M. Johnson, D. A. Berk, R. K. Jain, and W. M. Deen, "Hindered diffusion in agarose gels: test of effective medium model," Biophysical Journal, vol. 70, no. 2, pp. 1017-1023, 1996.

[50] T. Jouenne, O. Tresse, and G. A. Junter, "Agar-entrapped bacteria as an in vitro model of biofilms and their susceptibility to antibiotics," FEMS Microbiology Letters, vol. 119, no. 1-2, pp. 237-242, 1994.

[51] J. Hellriegel et al., "A biomimetic gellan-based hydrogel as a physicochemical biofilm model," Journal of Biomaterials and Nanobiotechnology, 2014.

[52] A. R. Johnsen and U. Karlson, "Evaluation of bacterial strategies to promote the bioavailability of polycyclic aromatic hydrocarbons," Applied Microbiology and Biotechnology, vol. 63, no. 4, pp. 452-459, 2004

[53] G. Bertini, K. Kerpen, and U. Telgheder, "Polysaccharide gels as surrogate for studying the desorption of phenanthrene from aquatic biofilms," International Journal of Research in Environ-mental Science and Technology, vol. 5, no. 2, pp. 57-61.

[54] A. S. Abdul and T. L. Gibson, "Adsorption-desorption of poly-cyclic aromatic hydrocarbons by two hydrogeologic materials," Hazardous Waste and Hazardous Materials, vol. 3, no. 2, p. 125, 1986.

[55] J. J. Piatt, D. A. Backhus, P. D. Capel, and S. J. Eisenreich, "Temperature-dependent sorption of naphthalene, phenan-threne, and pyrene to low organic carbon aquifer sediments," Environmental Science \& Technology, vol. 30, no. 3, pp. 751-760, 1996

[56] P. Elena. (2004). Investigation of transport and degradation processes of polycyclic aromatic hydrocarbons in biofilm. [Online]. Available: https://etd.ohiolink.edu/ap/10?0::no:10:p10_accession_num:ucin1092 930652

[57] D. M. Toro et al., "Reversible and resistant components of PCB adsorption-desorption: adsorbent concentration effects," Journal of Great Lakes Research, vol. 8, no. 2, pp. 336-349, 1982.

[58] K. J. Kennedy, J. Lu, and W. W. Mohn, "Biosorption of chlorophenols to anaerobic granular sludge," Water Research, vol. 26, no. 8, pp. 1085-1092, 1992.

[59] Y. Feng, J. H. Park, T. C. Voice, and S. A. Boyd, "Bioavailability of soil-sorbed biphenyl to bacteria," Environmental Science \& Technology, vol. 34, no. 10, pp. 1977-1984, 2000.

[60] Y. Zhang et al., "Extracellular polymeric substances govern the development of biofilm and mass transfer of polycyclic aromatic hydrocarbons for improved biodegradation," Bioresource Technology, vol. 193, pp. 274-280, 2015.

[61] M. Eriksson, G. Dalhammar, and W. W. Mohn, "Bacterial growth and biofilm production on pyrene," FEMS Microbiology Ecology, vol. 40, no. 1, pp. 21-27, 2002.

[62] L. Bastiaens et al., "Isolation of adherent polycyclic aromatic hydrocarbon (PAH)-degrading bacteria using PAH-sorbingcarriers," 
Applied and Environmental Microbiology, vol. 66, no. 5, pp. 1834-1843, 2000.

[63] T. S. Poeton, H. D. Stensel, and S. E. Strand, "Biodegradation of polyaromatic hydrocarbons by marine bacteria: effect of solid phase on degradation kinetics," Water Research, vol. 33, no. 3, pp. 868-880, 1999.

[64] B. Guieysse et al., "Degradation of acenaphthene, phenanthrene and pyrene in a packed-bed biofilm reactor," Applied Microbiology and Biotechnology, vol. 54, no. 6, pp. 826-831, 2000.

[65] Y. Seo et al., "The application of a mulch biofilm barrier for surfactant enhanced poly-cyclic aromatic hydrocarbon bioremediation," Environmental Pollution, vol. 157, no. 1, pp. 95-101, 2009.

[66] G. Kuncova, J. Triska, N. Vrchotova, and O. Podrazky, "The influence of immobilization of Pseudomonas sp. 2 on optical detection of polychlorinated biphenyls," Materials Science and Engineering: C, vol. 21, no. 1, pp. 195-201, 2002.

[67] F. Fava et al., "Dichlorobiphenyl degradation by an uncharacterized Pseudomonas species, strain CPE1, in a fixed film bioreactor," International Biodeterioration \& Biodegradation, vol. 37, no. 1, pp. 53-59, 1996.

[68] G. Mukerjee-Dhar, M. Shimura, and K. Kimbara, "Degradation of polychlorinated biphenyl by cells of Rhodococcusopacus strain TSP203 immobilized in alginate and in solution," Enzyme and Microbial Technology, vol. 23, no. 1, pp. 34-41, 1998

[69] J. Q. Borja et al., "Biodegradation of polychlorinated biphenyls using biofilm grown with biphenyl as carbon source in fluidized bed reactor," Chemosphere, vol. 64, no. 4, pp. 555-559, 2006.

[70] I. W. Sutherland, "Biofilm exopolysaccharides: A strong and sticky framework," Microbiology, vol. 147, no. 1, pp. 3-9, 2001.

[71] J. P. Bell and M. Tsezos, "Removal of hazardous organic pollutants by biomass adsorption," Journal (Water Pollution Con-trol Federation), pp. 191-198, 1987.

[72] M. Tsezos and J. P. Bell, "Comparison of the biosorption and desorption of hazardous organic pollutants by live and dead biomass," Water Research, vol. 23, no. 5, pp. 561-568, 1989.

[73] J. L. Zhou and C. J. Banks, "Mechanism of humic acid colour removal from natural waters by fungal biomass biosorption," Chemosphere, vol 27, no. 4, pp. 607-620, 1993.

[74] K. Karim and S. K. Gupta, "Biosorption of nitrophenols on anaerobic granular sludge," Environmental Technology, vol. 23, no. 12, pp 1379-1384, 2002.

[75] J. R. Lawrence et al., "Sorption and metabolism of selected herbicides in river biofilm communities," Canadian Journal of Microbiology, vol. 47 , no. 7, pp. 634-641, 2001

[76] E. L. Cussler, "Fundamentals of mass transfer," Diffusion: Mass Transfer in Fluid Systems, pp. 237-273, 1984.

[77] S. H. Woo, J. M. Park, and B. E. Rittmann, "Evaluation of the interaction between biodegradation and sorption of phenanthrene in soil-slurry systems," Biotechnology and Bioengineering, vol. 73, no. 1, pp. 12-24, 2001.

[78] M. L. Brusseau, A. L. Wood, and P. S. C. Rao, "Influence of organic cosolvents on the sorption kinetics of hydrophobic organic chemicals," Environmental Science \& Technology, vol. 25, no. 5, pp. 903-910, 1991.

[79] K. M. Carroll et al., "Application of a permeant/polymer diffusional model to the desorption of polychlorinated biphenyls from Hudson
River sediments," Environmental Science \& Technology, vol. 28, no. 2, pp. 253-258, 1994

[80] E. M. Lamoureux and B. J. Brownawell, "Chemical and biological availability of sediment-sorbed hydrophobic organic contaminants," Environmental Toxicology and Chemistry, vol. 18, no. 8, pp. 1733-1741, 1999.

[81] J. Birdwell, R. L. Cook, and L. J. Thibodeaux, "Desorption kinetics of hydrophobic organic chemicals from sediment to wa-ter: A review of data and models," Environmental Toxicology and Chemistry, vol. 26, no. 3, pp. 424-434, 2007.

[82] M. Uyttebroek, J. J. Ortega-Calvo, P. Breugelmans, and D. Springael, "Comparison of mineralization of solid-sorbedphenanthrene by polycyclic aromatic hydrocarbon (PAH)-degrading Mycobacterium spp. and Sphingomonas spp," Applied Microbiology and Biotechnology, vol. 72, no. 4, pp. 829-836, 2006.

[83] X. Sun and U. Ghosh, "The effect of activated carbon on partitioning, desorption, and biouptake of native polychlorinated biphenyls in four freshwater sediments," Environmental Toxicology and Chemistry, vol. 27, no. 11, pp. 2287-2295, 2008

[84] Y. Chai et al., "Modeling biphasic sorption and desorption of hydrophobic organic contaminants in sediments," Environmental Toxicology and Chemistry, vol. 25, no. 12, pp. 3133-3140, 2006.

[85] A. Oren and B. Chefetz, "Sorption-desorption behavior of polycyclic aromatic hydrocarbons in upstream and downstream river sediments," Chemosphere, vol. 61, no. 1, pp. 19-29, 2005.

[86] R. J. Grosser et al., "Effect of model sorptive phases on phenanthrene bio-degradation: different enrichment conditions influence bioa-vailability and selection of phenanthrene-degrading isolates," Applied and Environmental Microbiology, vol. 66, no. 7, pp. 2695-2702, 2000.

[87] J. L. Li and B. H. Chen, "Surfactant-mediated biodegrada-tion of polycyclic aromatic hydrocarbons," Materials, vol. 2, no. 1, pp. 76-94, 2009.

[88] S. Froehner et al., "Natural biofilms in freshwater ecosystem: indicators of the presence of polycyclic aromatic hydrocarbons," Water, Air, \& Soil Pollution, vol. 223, no. 7, pp. 3965-3973, 2012.

[89] M. Barret et al., "Kinetics and reversibility of micropollutant sorption in sludge," Journal of Environmental Monitoring, vol. 13, no. 10, pp. 2770-2774, 2011.

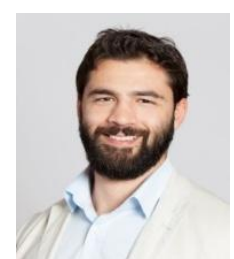

Giacomo Bertini was born in Prato, Italy on April 17 1983. In 2010 he achieved the master of science in microbial biotechnology at University of Florence, Italy. In the same year he moved to Essen, Germany, where in 2014 he achieved the title of doctor rerum Naturalium in microbiology as a PhD student of the Biofilm Centre at the University of Duisburg-Essen.

Dr. Bertini successfully accomplished an early stage research training within the marie curie FP7 initiative called ATWARM (Advanced Technologies for Water Resource Management).

During his academic experiences both in Italy and Germany, he studied the use of microbial biomasses as passive samplers for organic and inorganic pollutants in water systems.

$\mathrm{He}$ is currently working as chief's assistant at the Prozess Analysen Instrumente $\mathrm{GmbH}$ in Hipstedt, Germany. The company develops online monitor devices for drinking water, process water and wastewater. 